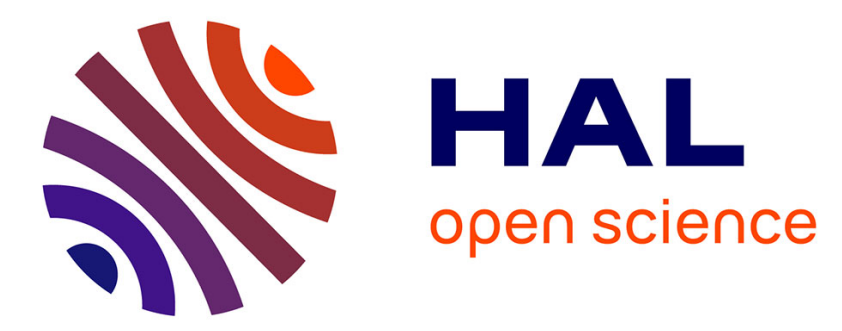

\title{
Let thy left brain know what thy right brain doeth: Inter-hemispheric compensation of functional deficits after brain damage
}

Paolo Bartolomeo, Michel Thiebaut de Schotten

\section{To cite this version:}

Paolo Bartolomeo, Michel Thiebaut de Schotten. Let thy left brain know what thy right brain doeth: Inter-hemispheric compensation of functional deficits after brain damage. Neuropsychologia, 2016 , 10.1016/j.neuropsychologia.2016.06.016 . hal-01346077

\section{HAL Id: hal-01346077 \\ https://hal.sorbonne-universite.fr/hal-01346077}

Submitted on 18 Jul 2016

HAL is a multi-disciplinary open access archive for the deposit and dissemination of scientific research documents, whether they are published or not. The documents may come from teaching and research institutions in France or abroad, or from public or private research centers.
L'archive ouverte pluridisciplinaire HAL, est destinée au dépôt et à la diffusion de documents scientifiques de niveau recherche, publiés ou non, émanant des établissements d'enseignement et de recherche français ou étrangers, des laboratoires publics ou privés. 


\title{
Let the left brain know what the right brain does: inter-hemispheric compensation of functional deficits after brain damage
}

Paolo Bartolomeo ${ }^{1}$ and Michel Thiebaut de Schotten ${ }^{1,3^{*}}$

${ }^{1}$ INSERM U1127, CNRS UMR 7225,Sorbonne Universités, and Université Pierre et Marie CurieParis 6, UMRS 1127, Institut du Cerveau et de la Moelle épinière (ICM), F-75013 Paris, France.

${ }^{2}$ AP-HP, Department of Neurology, IFR 70, Salpêtrière Hospital, Paris, France

${ }^{3}$ Brain Connectivity and Behaviour, Brain and Spine Institute, Paris France

*Corresponding author: michel.thiebaut@gmail.com

\begin{abstract}
Recent evidence revealed the importance of inter-hemispheric communication for the compensation of functional deficits after brain damage. This review summarises the biological consequences observed using histology as well as the longitudinal findings measured with magnetic resonance imaging methods in brain damaged animals and patients. In particular, we discuss the impact of post-stroke brain hyperactivity on functional recovery in relation to time. The reviewed evidence also suggests that the proportion of the preserved functional network both in the lesioned and in the intact hemispheres, rather than the simple lesion location, determines the extent of functional recovery. Hence, future research exploring longitudinal commissural changes in patients with brain damage may unveil potential biomarkers underlying functional recovery.
\end{abstract}

Keywords: Brain, Hemisphere, Stroke, Recovery, Asymmetry, Neurogenesis, White Matter, Connections, Phenotypes, Stratification, Longitudinal.

\section{Introduction}

Despite its symmetrical appearance, the human brain exhibits anatomical as well as functional hemispheric asymmetries (Concha et al., 2012). Frequently occurring after a lesion in the left rather than the right hemisphere, the observation of language deficits spurred the concept of 
hemispheric dominance (Broca, 1863). Similarly, the behaviour of right-brain damaged patients suggested a mirror organisation of visuo-spatial functions with the right hemisphere being responsible for spatial deficits (Gainotti et al., 1972). Decades of neuropsychological testing in patients with surgically separated hemispheres corroborated the hypothesis of hemispheric dominance (Sperry, 1974, 1981) and led to the attribution of Roger W. Sperry's Nobel prize in 1981 (Sperry, 1981) (see Fig. 1).

The concept of hemispheric dominance or brain lateralisation became so popular that it currently receives about 90 million hits on Google. However, recent progress in functional neuroimaging ( $\mathrm{AMRI}$ ) depicts a different story, in which far from being independent, both hemispheres work together to form a fine network, pooling its resources to elaborate language as well as spatial functions (Herve et al., 2013). For example, visual processing of words and faces, often considered to depend on specialized areas situated respectively in the left and in the right occipitotemporal cortex, is increasingly being understood as related to graded, not absolute, lateralisation patterns (Behrmann and Plaut, 2015). The (relative) left-lateralisation of readingrelated areas seems to result from their preferential connections with the left hemisphere language networks (Bouhali et al., 2014; Thiebaut de Schotten et al., 2014a). Learning to read would "push" face recognition areas towards the right hemisphere (Dehaene et al., 2010). Interhemispheric differences would, however, remain relative rather than absolute, with important variability across individuals (Behrmann and Plaut, 2015). Graded degrees of laterality of function can also result from transcortical cell assemblies, i.e., cluster of neurons which function in a coordinated manner across the hemispheres (Pulvermuller and Mohr, 1996). In fact, brain regions related to reading and to face recognition might be less discrete and more intertwisted than previously thought, and consist of anatomically alternated patchy modules along the ventral occipitotemporal cortex (Matsuo et al., 2015). 
How would this new understanding of the functioning of the brain account for the lateralisation of functional deficits? To answer this question our review will put forth evidence to show that a brain damage has consequences that spread well beyond the lesion site (section 1: Consequences of unilateral damage) and within the damaged functional networks (section 2 : The role of the unaffected hemisphere in cognitive recovery after stroke). From this perspective, we will argue that the brain's ability to handle damage relies on the proportion of the preserved functional network in both hemispheres, instead of the strict location of the lesion (section 3 : Inter-hemispheric communication).

\section{Consequences of unilateral brain damage}

During the acute phase of a vascular stroke, focal brain damage affects cortical activity not only locally, but also in anatomically intact areas that are connected to the lesion site (diaschisis; Carrera and Tononi, 2014; Feeney and Baron, 1986; Monakow, 1914a). Diaschisis is classically defined as a remote loss of excitability (Monakow, 1914b). Cerebral damage induces reduction of blood flow in (Weiller et al., 1993) and disconnection of (Metter et al., 1985) brain areas distant from the lesion that can easily be spotted using perfusion weighted imaging (Beauchamp et al., 1999). Reduction in cerebral blood flow will decrease the metabolism due to selective neuronal loss (Olsen et al., 1986; Weiller et al., 1993) in the lesioned hemisphere (i.e. ipsilateral diaschisis). Disconnections will reduce the metabolism because of neuronal deafferentation (Metter et al., 1985) in the lesioned hemisphere as well as in the unaffected hemisphere (i.e. transcortical diaschisis). These two phenomena are critical for functional recovery, because two subcortical lesion of similar appearance can have drastically different functional outcomes in patients, depending on their impact on distant cortical areas (Hillis et al., 2000; Hillis et al., 2002). 
However, increased excitability can also occur in connected areas, both in the lesioned hemisphere and in the unaffected hemisphere (Buchkremer-Ratzmann et al., 1996). Particularly, surface lesions are more likely to present with ipsilateral increased excitability, whereas deeper lesions will tend to involve also the contralateral hemisphere (Buchkremer-Ratzmann and Witte, 1997) through a complex modulation of specific receptors. Immunohistochemical studies in rats with photochemically induced cortical infarcts suggest that ipsilateral increased excitability is in part associated to the down-regulation of gamma-aminobutyric acid (GABA)A receptors alpha1, alpha2, alpha5 and gamma2 within the ipsilateral hemisphere, whereas up-regulation of receptors alpha3 would be linked to contralateral increased excitability. These post-stroke GABA receptor modulations are blocked by $\mathrm{N}$-methyl-d-aspartate-receptor (NMDA) antagonists (Redecker et al., 2002). This suggests that a sequential order of receptor modulation takes place in both hemispheres after a stroke, although the fine details about the pipeline of this chain reaction requires further characterisation at the cellular level (Paik and Yang, 2014).

At the macroscopic level, cortical hyperexcitability is identified using task-based functional MRI (Corbetta et al., 2005). Cortical hyperexcitability tends to appear in both hemispheres during the early weeks after a stroke, and to decrease thereafter. These processes may contribute to spontaneous functional recovery. However, they can also be maladaptive in the case of persistence after the first weeks post-stroke, and thereby correlate with poor behavioural recovery (Cramer, 2008). Thus, the significance of post-stroke hyperactivity for functional recovery varies according time. Four partially overlapping temporal epochs can be identified (Fig. 2): (1) an acute phase within hours of the stroke, characterised by local inflammation, oedema and distal diaschisis; (2) a subacute phase during the first weeks after the stroke, when most of the spontaneous recovery occurs and then plateaus, and the distal diaschisis peaks; (3) a chronic phase beginning weeks to months after the stroke, associated with a 'normalisation' of the activity and a stabilisation of the deficits (Cramer, 2008); (4) finally, several months after the 
injury, preliminary evidence suggests that a rewiring of white matter fibers may also occur, with axonal sprouting near the ischemic injury leading to novel connections to distant cortical targets (Dancause et al., 2005).

These distinct mechanisms may be associated with different forms of functional recovery. For instance, whereas motor deficits usually show a maximum recovery within 30 days, language and other high cognitive functions may improve well beyond this phase, up to a year after stroke (Cramer, 2008). This difference in recovery rate suggests that partly distinct mechanisms may be at work in motor and in cognitive recovery (Grefkes and Ward, 2014). Hence, the late occurrence of cortical rewiring might well have an essential role in the recovery of high cognitive function. This difference would also suggest that specific recovery mechanisms are in place for functions that developed later along the evolutionary tree.

\section{The role of the unaffected hemisphere in cognitive recovery after stroke}

Functional MRI revealed that language and visuospatial functions, although asymmetrically distributed, are functions elaborated within bilateral networks in the brain (Tzourio-Mazoyer et al., 2015) (Fig. 3). Therefore, a unilateral lesion can partially damage both the language and visuospatial networks. While the unaffected hemisphere has been hypothesised as playing a key role in functional recovery, literature reports contradictory evidence the role of the contralesional hemisphere in recovery from language disorders (review in Gainotti, 2015) or visual neglect (review in Bartolomeo, 2015).

Follow-up studies on patients with subsequent bilateral strokes provided a first line of evidence indicating the important compensatory role of the hemisphere contralateral to the first lesion. Indeed, when a second lesion occurs in the contralesional hemisphere, patients' on-going 
recovery from the effects of the first lesion is often disrupted. These studies mainly concerned patients with a first lesion in the left hemisphere and consequent aphasic disorders (Gainotti, 2015; Heilman et al., 1979) or pure alexia (Bartolomeo et al., 1998, 2003). In keeping with these findings, using transcranial magnetic stimulation Coslett and Monsul (1994) were able to disrupt oral reading in a partially recovered pure alexic patient by interfering with the function of the right hemisphere, but not with that of the left hemisphere. However, other non-invasive brain stimulation studies on patients produced mixed results. For example, both inhibitory (Kindler et al., 2012) and excitatory (Chieffo et al., 2014) magnetic stimulation over the right homologous Broca's region have been reported to improve naming in aphasic patients. In a similar way, neuroimaging studies of stroke patients did not provide conclusive evidence on the role of the healthy hemisphere in cognitive recovery. A further example is that the improvement of language in post-stroke aphasia was found to correlate with increased BOLD response in the right homologue of Broca's area during the acute phase, and to a redirection of BOLD activation in perilesional areas in the left hemisphere during the chronic phase (Saur et al., 2006b). These and other similar findings confirm the key role that time plays within post-stroke functional recovery through its contribution to activity in the unaffected hemisphere.

There is similarly conflicting evidence concerning the evolution of visual neglect after right hemisphere damage. On the one hand, $\mathrm{fMRI}$ results indicated a relative hyperactivity of left dorsal fronto-parietal networks in subacute neglect patients, which would provoke an attentional bias towards right-sided objects (Urbanski and Bartolomeo, 2008) and neglect of left-sided items (Corbetta et al., 2005; He et al., 2007); consistent with this hypothesis, suppressive transcranial magnetic stimulation over left fronto-parietal regions correlated with an improvement of patients' performance on cancellation tests (Koch et al., 2008). On the other hand, a widespread hypometabolism in both the lesioned and the intact hemispheres has also been demonstrated in chronic neglect (Fiorelli et al., 1991; Pantano et al., 1992; Perani et al., 1993). Neglect recovery has been shown to correlate with restoration of normal metabolism not only in the unaffected 
regions of the right hemisphere, but also in the left hemisphere (Pantano et al., 1992; Perani et al., 1993; see also Wilke et al., 2012, for compelling evidence in the monkey). This conflicting evidence may well be due to the timing of the studies with regard to the patients' epoch of recovery (subacute vs. chronic).

Another source of variance in recovery may be the predisposition of other areas of the functional network to compensate for the deficit. These vicariant structures can, for example, already be dysfunctional through comorbid disorders occurring before the stroke. This has been illustrated by Levine et al (1986), who followed up 9 patients with a stroke in the right hemisphere. In the subacute phase (2 - 4 weeks post-event) the severity of left neglect increased as well as both the size of the lesion and the degree of pre-morbid diffuse cortical atrophy. Patients with cortical atrophy showed poor recovery from neglect over 3 to 5 months. The authors concluded that lesion size affects recovery through its extent to potential ipsilateral vicariant areas. Controlateral vicariant areas, however, might be affected by premorbid atrophy that further reduces the quality of the recovery.

Finally, some individual brains may have a better predisposition to recover than others. Recently, Forkel et al. (2014) demonstrated that the phenotype of the structural network supporting language (i.e. arcuate fasciculus) may interact with recovery (Fig. 4). In a group of 16 patients with a left hemisphere stroke, they showed that the patients having a more bilateral structural network for language were more likely to recover from aphasia when controlling for age, gender and lesion size. By analogy, these results suggest an interesting hypothesis on the lateralisation of structural networks supporting visuospatial processing (Thiebaut de Schotten et al., 2011) as a predisposition to recover from left neglect: the less right-lateralized are the II and III branches of the Superior Longitudinal Fasciculus (SLF), the better patients should be able to recover from left neglect signs. More generally, these results highlight the importance of establishing a clear patient stratification in order to provide a more personalised treatment. 


\section{Inter-hemispheric communication}

Cognitive deficits typically reflect network-based dysfunctions, rather than local neural damage (Catani and Mesulam, 2008; Doricchi et al., 2008; Geschwind, 1965a, b). This important, yet general and relevant point, does not often receive enough attention. The network-based nature of cognitive deficits leaves room for non-lesioned nodes or networks to compensate for the impaired function. However, for this vicariance to be successful, the unaffected nodes/networks must be connected with the rest of the system. In the particular case of inter-hemispheric compensation of cognitive deficits, fast and efficient communication between the healthy and the lesioned hemisphere is likely to be a mandatory condition.

The most important anatomical structure subserving inter-hemispheric communication is the corpus callosum (Glickstein and Berlucchi, 2008; Zaidel and lacoboni, 1997). Indeed, impaired callosal function may contribute to signs of visual neglect in right brain-damaged patients. As originally suggested by Norman Geschwind (1965b), an isolated left hemisphere might in some cases take over the control of performance, with consequent rightward attentional bias (Bartolomeo, 2007; Berlucchi et al., 1997). It is, for example, possible that inappropriate activity of left prefrontal cortex in neglect patients partly explains their lack of exploration/detection of left-sided events (Rastelli et al., 2013), especially when the left prefrontal cortex does not receive the appropriate input from more posterior or contralateral regions (Bartolomeo, 2015). Empirical support to this hypothesis comes from the clinical observation of a regression of left neglect signs in a patient with right parietal damage, after a second lesion occurred in the left prefrontal cortex (Vuilleumier et al., 1996). Sensory neglect can also be induced through posterior callosal damage, combined with damage to the visual cortex or visual pathways in the right hemisphere, such that the left hemisphere is deafferented from visual information (Gaffan and Hornak, 1997; 
Park et al., 2006; Tomaiuolo et al., 2010). A study on 11 right brain-damaged patients found that microstructural damage of the posterior corpus callosum, as estimated by diffusion MRI, correlated with the clinical severity of neglect (Bozzali et al., 2012). Another diffusion MRI study found microstructural alterations of the corpus callosum adjacent to the left, unaffected hemisphere in 12 patients with chronic neglect (Umarova et al., 2014). Similarly, damage to the corpus callosum may contribute to aphasia (Saba and Blum, 2014) through a deafferentation of left language areas from the right hemisphere (Ishizaki et al., 2012). However these cases are rare, usually presented as single case reports, which make it difficult to draw general conclusions (Shallice, 1988).

The fact that interhemispheric disconnection may compromise recovery was further documented by Lunven et al (2015), who recently obtained anatomical evidence on 45 patients with unilateral strokes in the right hemisphere. Patients were assessed twice for neglect, first at the subacute phase (less than 3 months after onset) and then at the chronic phase ( $>1$ year). Their lesions were assessed with MRI including diffusion sequences. Additionally, after masking each patient's lesion, Lunven et al (2015) performed Tract-Based Spatial Statistics (Smith et al., 2006) to obtain a voxelwise statistical analysis of the fractional anisotropy (FA) data. Twenty-seven patients had signs of visual neglect at initial testing. Only 10 of these patients had recovered from neglect at follow-up. When compared with patients without neglect, the group including all subacute neglect patients had decreased FA in the II and III branches of the right SLF, as well as in the splenium of the corpus callosum. The subgroup of chronic patients showed reduced FA in a portion the splenium, the forceps major, which provides inter-hemispheric communication between regions of the occipital lobe and of the superior parietal lobules. The severity of neglect inversely correlated with FA values in SLF II/III for subacute patients and in its caudal portion for chronic patients. These results confirmed a key role of fronto-parietal disconnection in the emergence and chronic persistence of neglect (Bartolomeo et al., 2007; Doricchi et al., 2008; 
Doricchi and Tomaiuolo, 2003; Thiebaut de Schotten et al., 2008; Thiebaut de Schotten et al., 2014b), but also demonstrated an implication of caudal interhemispheric disconnection in chronic neglect. Lunven et al. (2015) concluded that splenial disconnection may prevent frontoparietal networks in the left hemisphere from resolving the activity imbalance with their righthemisphere counterparts (Corbetta and Shulman, 2011), thus leading to persistent neglect.

The demonstration of the importance of the anatomically intact callosal connections for the recovery of cognitive deficits underlying neglect signs suggest that some of the discrepancies in the literature on the effects of activity in the unaffected hemisphere may depend on differences in interhemispheric communication. In the case of neglect, activity in an isolated left hemisphere is unlikely to take into account information coming from the left side, thus aggravating neglect. A similar case may be made for language disorders, where activity in an isolated right hemisphere with degraded input from the lesioned language networks may be less efficient for, or even detrimental to, language recovery. Thus, the adaptive or maladaptive nature of activity in the unaffected hemisphere may also depend on its capability of communicating with the lesioned hemisphere.

The role of interhemispheric communication for brain recovery extends well beyond visual neglect. A resting state fMRI connectivity study on 23 patients with first-ever acute strokes demonstrated that decreased interhemispheric functional connectivity between homologous fronto-parietal regions correlated with deficits in the detection of contralesional targets and decreased motor function of the upper extremity (Carter et al., 2010). In a similar way, in 10 stroke survivors recovery of the sensation of touch correlated with interhemispheric functional connectivity between regions of the somatosensory system, and with visual and frontal areas (Bannister et al., 2015). Surprisingly, to our knowledge no studies reported language recovery associated with changes in interhemispheric communication; however many studies describe 
increased functional activation in the contralesional hemisphere in aphasics (Crosson et al., 2007), associated with language recovery (Cao et al., 1999; Weiller et al., 1995). Contralesional activations, however, seems to disappear at the chronic stage of the stroke, when solely left activation remains (Saur et al., 2006a). This inter-hemispheric shift of activations related to aphasia recovery suggests an important involvement of the inter-hemispheric structural connectivity in the evolution of these longitudinal changes (Thompson and den Ouden, 2008). It is therefore predictable that a decrease of structural or functional connectivity of the corpus callosum might be correlated to poor language recovery after a stroke.

\section{Conclusion}

In this review we have summarised facts and findings demonstrating that damage to the brain has several short and long-term effects in regions far outside the lesion. These effects extend mostly within a functional network distributed among both hemispheres. Although functional distribution in the brain might seem to be similar in most people, individual variations in brain organisation might provide a valuable advantage when it comes to recovery from a brain lesion. Finally, interhemispheric communication may well be a key component of recovery processes, by linking up damaged structures with most of the remaining healthy functional network. Future research should explore longitudinal commissural changes in patients with brain damage, in order to unveil potential biomarkers of functional recovery. 


\section{Acknowledgments:}

We thank Lauren Sakuma for useful discussion. This work was funded by the 'Agence Nationale de la Recherche' (grant number ANR-13-JSV4-0001-01). Additional support came from the program “Investissements d'avenir" ANR-10-IAIHU-06.

\section{References}

Bannister, L., Crewther, S., Gavrilescu, M., Carey, L. Improvement in Touch Sensation after Stroke is Associated with Resting Functional Connectivity Changes. Frontiers in Neurology 6, 2015.

Bartolomeo, P. Visual neglect. Curr Opin Neurol 20 (4): 381-386, 2007.

Bartolomeo, P. Spatially biased decisions: Toward a dynamic interactive model of visual neglect. in: Tracy, J.I., Hampstead, B., Sathian, K. (Eds.), Plasticity of Cognition in Neurologic Disorders. Oxford University Press: Oxford, 2015. pp. 299-322.

Bartolomeo, P., Bachoud-Lévi, A.C., Degos, J.D., Boller, F. Disruption of residual reading capacity in a pure alexic patient after a mirror-image right hemispheric lesion. Neurology 50 (1): 286-288, 1998.

Bartolomeo, P., Bachoud-Lévi, A.C., Degos, J.D., Boller, F. Right hemisphere contributions to residual reading in pure alexia: Evidence from a patient with subsequent bilateral strokes. in: Zaidel, E., Iacoboni, M. (Eds.), The Parallel Brain: The Cognitive Neuroscience of the Corpus Callosum. The MIT Press: Cambridge, MA, 2003. pp. 500-506.

Bartolomeo, P., Thiebaut de Schotten, M., Doricchi, F. Left unilateral neglect as a disconnection syndrome. Cereb Cortex 17 (11): 2479-2490, 2007.

Beauchamp, N.J., Jr., Barker, P.B., Wang, P.Y., vanZijl, P.C. Imaging of acute cerebral ischemia. Radiology 212 (2): 307-324, 1999.

Behrmann, M., Plaut, D.C. A vision of graded hemispheric specialization. Ann N Y Acad Sci 1359 (1): 30-46, 2015.

Berlucchi, G., Aglioti, S., Tassinari, G. Rightward attentional bias and left hemisphere dominance in a cue- target light detection task in a callosotomy patient. Neuropsychologia 35 (7): 941-952, 1997.

Bouhali, F., Thiebaut de Schotten, M., Pinel, P., Poupon, C., Mangin, J.F., Dehaene, S., Cohen, L. Anatomical connections of the visual word form area. J Neurosci 34 (46): 15402-15414, 2014. Bozzali, M., Mastropasqua, C., Cercignani, M., Giulietti, G., Bonni, S., Caltagirone, C., Koch, G. Microstructural damage of the posterior corpus callosum contributes to the clinical severity of neglect. PLoS One 7 (10): e48079, 2012.

Broca, P. Localisation des fonctions cérébrales. Siège du langage articulé. Bulletin de la Société Anthropologique 4: 200-208, 1863.

Buchkremer-Ratzmann, I., August, M., Hagemann, G., Witte, O.W. Electrophysiological transcortical diaschisis after cortical photothrombosis in rat brain. Stroke 27 (6): 1105-1109; discussion 1109-1111, 1996. 
Buchkremer-Ratzmann, I., Witte, O.W. Extended brain disinhibition following small photothrombotic lesions in rat frontal cortex. Neuroreport 8 (2): 519-522, 1997.

Cao, Y., Vikingstad, E.M., George, K.P., Johnson, A.F., Welch, K.M. Cortical language activation in stroke patients recovering from aphasia with functional MRI. Stroke 30 (11): 2331-2340, 1999. Carrera, E., Tononi, G. Diaschisis: past, present, future. Brain 137 (Pt 9): 2408-2422, 2014.

Carter, A.R., Astafiev, S.V., Lang, C.E., Connor, L.T., Rengachary, J., Strube, M.J., Pope, D.L.W., Shulman, G.L., Corbetta, M. Resting interhemispheric functional magnetic resonance imaging connectivity predicts performance after stroke. Ann Neurol 67 (3): 365-375, 2010.

Catani, M., Mesulam, M.-M. Special Issue on "Brain Hodology - Revisiting disconnection approaches to disorders of cognitive function". Cortex 44 (8): 911-1136, 2008.

Chieffo, R., Ferrari, F., Battista, P., Houdayer, E., Nuara, A., Alemanno, F., Abutalebi, J., Zangen, A., Comi, G., Cappa, S.F., Leocani, L. Excitatory deep transcranial magnetic stimulation with $\mathrm{H}$-coil over the right homologous Broca's region improves naming in chronic post-stroke aphasia. Neurorehabil Neural Repair 28 (3): 291-298, 2014.

Concha, M.L., Bianco, I.H., Wilson, S.W. Encoding asymmetry within neural circuits. Nat Rev Neurosci 13 (12): 832-843, 2012.

Corbetta, M., Kincade, M.J., Lewis, C., Snyder, A.Z., Sapir, A. Neural basis and recovery of spatial attention deficits in spatial neglect. Nature Neuroscience 8 (11): 1603-1610, 2005.

Corbetta, M., Shulman, G.L. Spatial neglect and attention networks. Annu Rev Neurosci 34: 569599, 2011.

Coslett, H.B., Monsul, N. Reading with the right hemisphere: Evidence from transcranial magnetic stimulation. Brain and Language 46: 198-211, 1994.

Cramer, S.C. Repairing the human brain after stroke: I. Mechanisms of spontaneous recovery. Ann Neurol 63 (3): 272-287, 2008.

Crosson, B., McGregor, K., Gopinath, K.S., Conway, T.W., Benjamin, M., Chang, Y.L., Moore, A.B., Raymer, A.M., Briggs, R.W., Sherod, M.G., Wierenga, C.E., White, K.D. Functional MRI of language in aphasia: a review of the literature and the methodological challenges. Neuropsychology review 17 (2): 157-177, 2007.

Dancause, N., Barbay, S., Frost, S.B., Plautz, E.J., Chen, D., Zoubina, E.V., Stowe, A.M., Nudo, R.J. Extensive cortical rewiring after brain injury. The Journal of neuroscience 25 (44): 1016710179, 2005.

Deglin, V. Our split brain. UNESCO Courier 29 (1): 4-14, 16, 31-32, 1976.

Dehaene, S., Pegado, F., Braga, L.W., Ventura, P., Nunes Filho, G., Jobert, A., DehaeneLambertz, G., Kolinsky, R., Morais, J., Cohen, L. How learning to read changes the cortical networks for vision and language. Science 330 (6009): 1359-1364, 2010.

Doricchi, F., Thiebaut de Schotten, M., Tomaiuolo, F., Bartolomeo, P. White matter (dis)connections and gray matter (dys)functions in visual neglect: Gaining insights into the brain networks of spatial awareness. Cortex 44 (8): 983-995, 2008.

Doricchi, F., Tomaiuolo, F. The anatomy of neglect without hemianopia: a key role for parietalfrontal disconnection? Neuroreport 14 (17): 2239-2243, 2003.

Feeney, D.M., Baron, J.C. Diaschisis. Stroke 17 (5): 817-830, 1986.

Fiorelli, M., Blin, J., Bakchine, S., Laplane, D., Baron, J.C. PET studies of cortical diaschisis in patients with motor hemineglect. Journal of the Neurological Sciences 104: 135-142, 1991.

Forkel, S.J., Thiebaut de Schotten, M., Dell'Acqua, F., Kalra, L., Murphy, D.G., Williams, S.C., Catani, M. Anatomical predictors of aphasia recovery: a tractography study of bilateral perisylvian language networks. Brain 137 (Pt 7): 2027-2039, 2014.

Gaffan, D., Hornak, J. Visual neglect in the monkey. Representation and disconnection. Brain 120 ( Pt 9): 1647-1657, 1997.

Gainotti, G. Contrasting opinions on the role of the right hemisphere in the recovery of language.

A critical survey. Aphasiology (ahead-of-print): 1-18, 2015. 
Gainotti, G., Messerli, P., Tissot, R. Qualitative analysis of unilateral spatial neglect in relation to laterality of cerebral lesions. J Neurol Neurosurg Psychiatry 35 (4): 545-550, 1972.

Geschwind, N. Disconnexion syndromes in animals and man - Part I. Brain 88: 237-294, 1965a. Geschwind, N. Disconnexion syndromes in animals and man - Part II. Brain 88: 585-644, 1965b. Glickstein, M., Berlucchi, G. Classical disconnection studies of the corpus callosum. Cortex 44 (8): 914-927, 2008.

Grefkes, C., Ward, N.S. Cortical Reorganization After Stroke: How Much and How Functional? The Neuroscientist 20 (1): 56-70, 2014.

He, B.J., Snyder, A.Z., Vincent, J.L., Epstein, A., Shulman, G.L., Corbetta, M. Breakdown of functional connectivity in frontoparietal networks underlies behavioral deficits in spatial neglect. Neuron 53 (6): 905-918, 2007.

Heilman, K.M., Rothi, L., Campanella, D., Wolfson, S. Wernicke's and global aphasia without alexia. Archives of Neurology 36: 129-133, 1979.

Herve, P.Y., Zago, L., Petit, L., Mazoyer, B., Tzourio-Mazoyer, N. Revisiting human hemispheric specialization with neuroimaging. Trends Cogn Sci 17 (2): 69-80, 2013.

Hillis, A.E., Barker, P.B., Beauchamp, N.J., Gordon, B., Wityk, R.J. MR perfusion imaging reveals regions of hypoperfusion associated with aphasia and neglect. Neurology 55 (6): $782-$ 788, 2000.

Hillis, A.E., Wityk, R.J., Barker, P.B., Beauchamp, N.J., Gailloud, P., Murphy, K., Cooper, O., Metter, E.J. Subcortical aphasia and neglect in acute stroke: the role of cortical hypoperfusion. Brain 125 (Pt 5): 1094-1104, 2002.

Ishizaki, M., Ueyama, H., Nishida, Y., Imamura, S., Hirano, T., Uchino, M. Crossed aphasia following an infarction in the right corpus callosum. Clinical neurology and neurosurgery 114 (2): 161-165, 2012.

Kindler, J., Schumacher, R., Cazzoli, D., Gutbrod, K., Koenig, M., Nyffeler, T., Dierks, T., Müri, R.M. Theta Burst Stimulation Over the Right Broca's Homologue Induces Improvement of Naming in Aphasic Patients. Stroke 43 (8): 2175-2179, 2012.

Koch, G., Oliveri, M., Cheeran, B., Ruge, D., Lo Gerfo, E., Salerno, S., Torriero, S., Marconi, B., Mori, F., Driver, J., Rothwell, J.C., Caltagirone, C. Hyperexcitability of parietal-motor functional connections in the intact left-hemisphere of patients with neglect. Brain 131 (Pt 12): 3147-3155, 2008.

Levine, D.N., Warach, J.D., Benowitz, L., Calvanio, R. Left spatial neglect: Effects of lesion size and premorbid brain atrophy on severity and recovery following right cerebral infarction. Neurology 36: 362-366, 1986.

Lunven, M., Thiebaut De Schotten, M., Bourlon, C., Duret, C., Migliaccio, R., Rode, G., Bartolomeo, P. White matter lesional predictors of chronic visual neglect: a longitudinal study. Brain 138 (Pt 3): 746-760, 2015.

Matsuo, T., Kawasaki, K., Kawai, K., Majima, K., Masuda, H., Murakami, H., Kunii, N., Kamitani, Y., Kameyama, S., Saito, N., Hasegawa, I. Alternating zones selective to faces and written words in the human ventral occipitotemporal cortex. Cereb Cortex 25 (5): 1265-1277, 2015.

Metter, E.J., Mazziotta, J.C., Itabashi, H.H., Mankovich, N.J., Phelps, M.E., Kuhl, D.E. Comparison of glucose metabolism, x-ray CT, and postmortem data in a patient with multiple cerebral infarcts. Neurology 35 (12): 1695-1701, 1985.

Monakow, C.V. Die Lokalisation im Grosshirn und der Abbau der Funktion durch kortikale Herde. J. F. Bergmann, 1914a.

Monakow, C.V. Die Lokalisation im Grosshirn und der Funktion durch kortikale Herde. Verlag von J.F. Bergmann: Wiesbaden, 1914b.

Olsen, T.S., Bruhn, P., Öberg, R.G.E. Cortical hypoperfusion as a possible cause of 'subcortical aphasia'. Brain 109 (3): 393-410, 1986.

Paik, N.J., Yang, E. Role of GABA plasticity in stroke recovery. Neural regeneration research 9 (23): 2026-2028, 2014. 
Pantano, P., Di Piero, V., Fieschi, C., Judica, A., Guariglia, C., Pizzamiglio, L. Pattern of CBF in the rehabilitation of visual spatial neglect. International Journal of Neurosciences 66: 153-161, 1992.

Park, K.C., Lee, B.H., Kim, E.J., Shin, M.H., Choi, K.M., Yoon, S.S., Kwon, S.U., Chung, C.S., Lee, K.H., Heilman, K.M., Na, D.L. Deafferentation-disconnection neglect induced by posterior cerebral artery infarction. Neurology 66 (1): 56-61, 2006.

Perani, D., Vallar, G., Paulesu, E., Alberoni, M., Fazio, F. Left and right hemisphere contribution to recovery from neglect after right hemisphere damage - An $\left[{ }^{18} \mathrm{~F}\right] \mathrm{FDG}$ PET study of two cases. Neuropsychologia 31 (2): 115-125, 1993.

Pulvermuller, F., Mohr, B. The concept of transcortical cell assemblies: a key to the understanding of cortical lateralization and interhemispheric interaction. Neurosci Biobehav Rev 20 (4): 557-566, 1996.

Rastelli, F., Tallon-Baudry, C., Migliaccio, R., Toba, M.N., Ducorps, A., Pradat-Diehl, P., Duret, C., Dubois, B., Valero-Cabré, A., Bartolomeo, P. Neural dynamics of neglected targets in patients with right hemisphere damage. Cortex 49 (7): 1989-1996, 2013.

Redecker, C., Wang, W., Fritschy, J.M., Witte, O.W. Widespread and long-lasting alterations in GABA(A)-receptor subtypes after focal cortical infarcts in rats: mediation by NMDA-dependent processes. Journal of cerebral blood flow and metabolism : official journal of the International Society of Cerebral Blood Flow and Metabolism 22 (12): 1463-1475, 2002.

Saba, S., Blum, S. Aphasia due to isolated infarction of the corpus callosum. BMJ Case Rep 2014, 2014.

Saur, D., Lange, R., Baumgaertner, A., Schraknepper, V., Willmes, K., Rijntjes, M., Weiller, C. Dynamics of language reorganization after stroke. Brain 129 (Pt 6): 1371-1384, 2006a.

Saur, D., Lange, R., Baumgaertner, A., Schraknepper, V., Willmes, K., Rijntjes, M., Weiller, C. Dynamics of language reorganization after stroke, 2006b.

Shallice, T. From neuropsychology to mental structure. Cambridge University Press: Cambridge, 1988.

Smith, S.M., Jenkinson, M., Johansen-Berg, H., Rueckert, D., Nichols, T.E., Mackay, C.E., Watkins, K.E., Ciccarelli, O., Cader, M.Z., Matthews, P.M., Behrens, T.E. Tract-based spatial statistics: voxelwise analysis of multi-subject diffusion data. Neuroimage 31 (4): 1487-1505, 2006.

Sperry, R.W. Lateral Specialization in the Surgically Separated Hemispheres. Rockefeller University Press: New York, 1974.

Sperry, R.W. The Nobel Prize in Physiology or Medicine 1981. The nobel assembly at the Karolinska Institute: Stockholm, 1981.

Thiebaut de Schotten, M., Cohen, L., Amemiya, E., Braga, L.W., Dehaene, S. Learning to read improves the structure of the arcuate fasciculus. Cereb Cortex 24 (4): 989-995, 2014a.

Thiebaut de Schotten, M., Dell'Acqua, F., Forkel, S.J., Simmons, A., Vergani, F., Murphy, D.G., Catani, M. A lateralized brain network for visuospatial attention. Nat Neurosci 14 (10): 12451246, 2011.

Thiebaut de Schotten, M., Kinkingnehun, S., Delmaire, C., Lehericy, S., Duffau, H., Thivard, L., Volle, E., Levy, R., Dubois, B., Bartolomeo, P. Visualization of disconnection syndromes in humans. Cortex 44 (8): 1097-1103, 2008.

Thiebaut de Schotten, M., Tomaiuolo, F., Aiello, M., Merola, S., Silvetti, M., Lecce, F., Bartolomeo, P., Doricchi, F. Damage to white matter pathways in subacute and chronic spatial neglect: a group study and 2 single-case studies with complete virtual "in vivo" tractography dissection. Cereb Cortex 24 (3): 691-706, 2014b.

Thompson, C.K., den Ouden, D.B. Neuroimaging and recovery of language in aphasia. Current neurology and neuroscience reports 8 (6): 475-483, 2008. 
Tomaiuolo, F., Voci, L., Bresci, M., Cozza, S., Posteraro, F., Oliva, M., Doricchi, F. Selective visual neglect in right brain damaged patients with splenial interhemispheric disconnection. Experimental Brain Research 206 (2): 209-217, 2010.

Tzourio-Mazoyer, N., Joliot, M., Marie, D., Mazoyer, B. Variation in homotopic areas' activity and inter-hemispheric intrinsic connectivity with type of language lateralization: an FMRI study of covert sentence generation in 297 healthy volunteers. Brain Struct Funct, 2015.

Umarova, R.M., Reisert, M., Beier, T.U., Kiselev, V.G., Kloppel, S., Kaller, C.P., Glauche, V., Mader, I., Beume, L., Hennig, J., Weiller, C. Attention-network specific alterations of structural connectivity in the undamaged white matter in acute neglect. Hum Brain Mapp, 2014.

Urbanski, M., Bartolomeo, P. Line bisection in left neglect: the importance of starting right. Cortex 44 (7): 782-793, 2008.

Vuilleumier, P., Hester, D., Assal, G., Regli, F. Unilateral spatial neglect recovery after sequential strokes. Neurology 46 (1): 184-189, 1996.

Weiller, C., Isensee, C., Rijntjes, M., Huber, W., Muller, S., Bier, D., Dutschka, K., Woods, R.P., Noth, J., Diener, H.C. Recovery from Wernicke's aphasia: a positron emission tomographic study. Ann Neurol 37 (6): 723-732, 1995.

Weiller, C., Willmes, K., Reiche, W., Thron, A., Isensee, C., Buell, U., Ringelstein, E.B. The case of aphasia or neglect after striatocapsular infarction. Brain 116 ( Pt 6): 1509-1525, 1993.

Wilke, M., Kagan, I., Andersen, R.A. Functional imaging reveals rapid reorganization of cortical activity after parietal inactivation in monkeys. Proceedings of the National Academy of Sciences 109 (21): 8274-8279, 2012.

Yarkoni, T., Poldrack, R.A., Nichols, T.E., Van Essen, D.C., Wager, T.D. Large-scale automated synthesis of human functional neuroimaging data. Nat Methods 8 (8): 665-670, 2011.

Zaidel, E., lacoboni, M. The Parallel Brain: The Cognitive Neuroscience of the Corpus Callosum. The MIT Press: Cambridge, MA, 1997.

\section{Figure captions}

Fig. 1. Roger W. Sperry's illustration of the functional specialisation of both cerebral hemispheres. The left hemisphere is dominant for speech, writing and calculations whereas the right hemisphere is rather dominant for spatial perception, word comprehension, and non-verbal concept formation (Deglin, 1976) (Illustration from the Nobel Committee for Physiology or Medicine, based on "Impact of Science on Society" published by UNESCO. (C) the Nobel Committee)

Fig. 2. Four temporal epochs for the spontaneous changes in the brain after a unilateral stroke (adapted from Cramer, 2008). Red background corresponds to acute stages of the stroke, yellow to subacute stages, blue to chronic stages, and pink to several months after the stroke. 
Fig. 3. Meta-analyses of functional MRI studies reporting activations related to language tasks (885 studies) and spatial tasks (1157 studies) in both hemispheres (for meta-analyses methods see Yarkoni et al., 2011; http://neurosynth.org).

Fig. 4. Anatomical variability in perisylvian white matter anatomy and its relation to post-stroke language recovery. The right long segment of the arcuate fasciculus is shown for three patients presenting with different degrees of language recovery at 6 months. These patients are indicated in the regression plot of the volume of the right long segment plotted against the longitudinal aphasia quotient (AQ) (corrected for age, sex and lesion size, adapted from Forkel et al., 2014). 


\section{language}
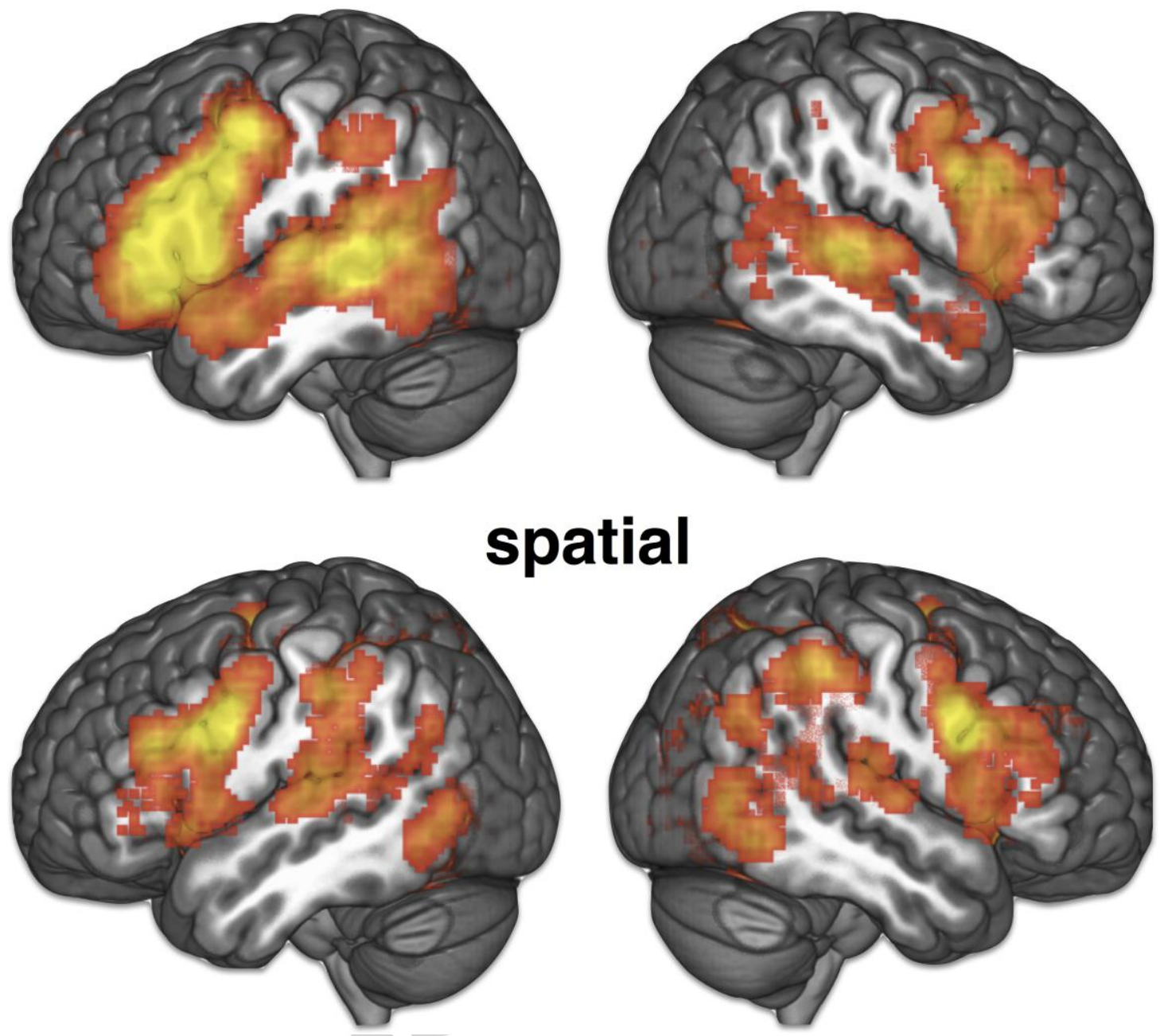

atial

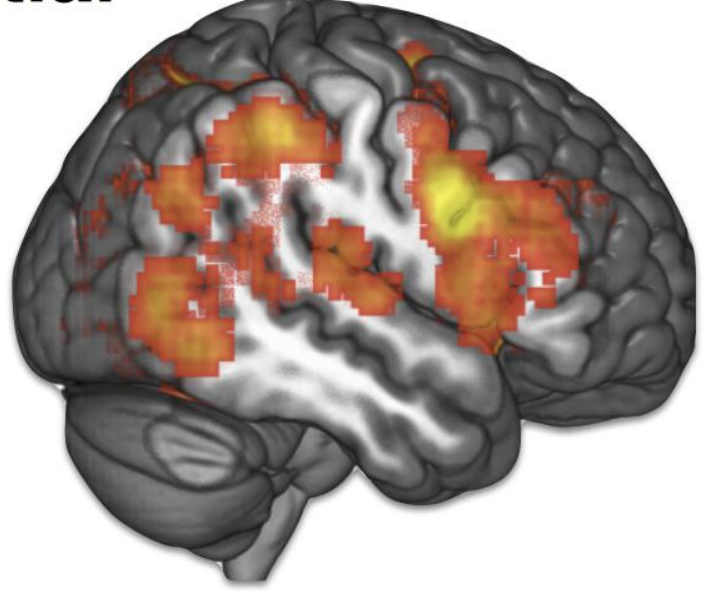

$\mathrm{p}$ $<0.001$ $<0.01$ 


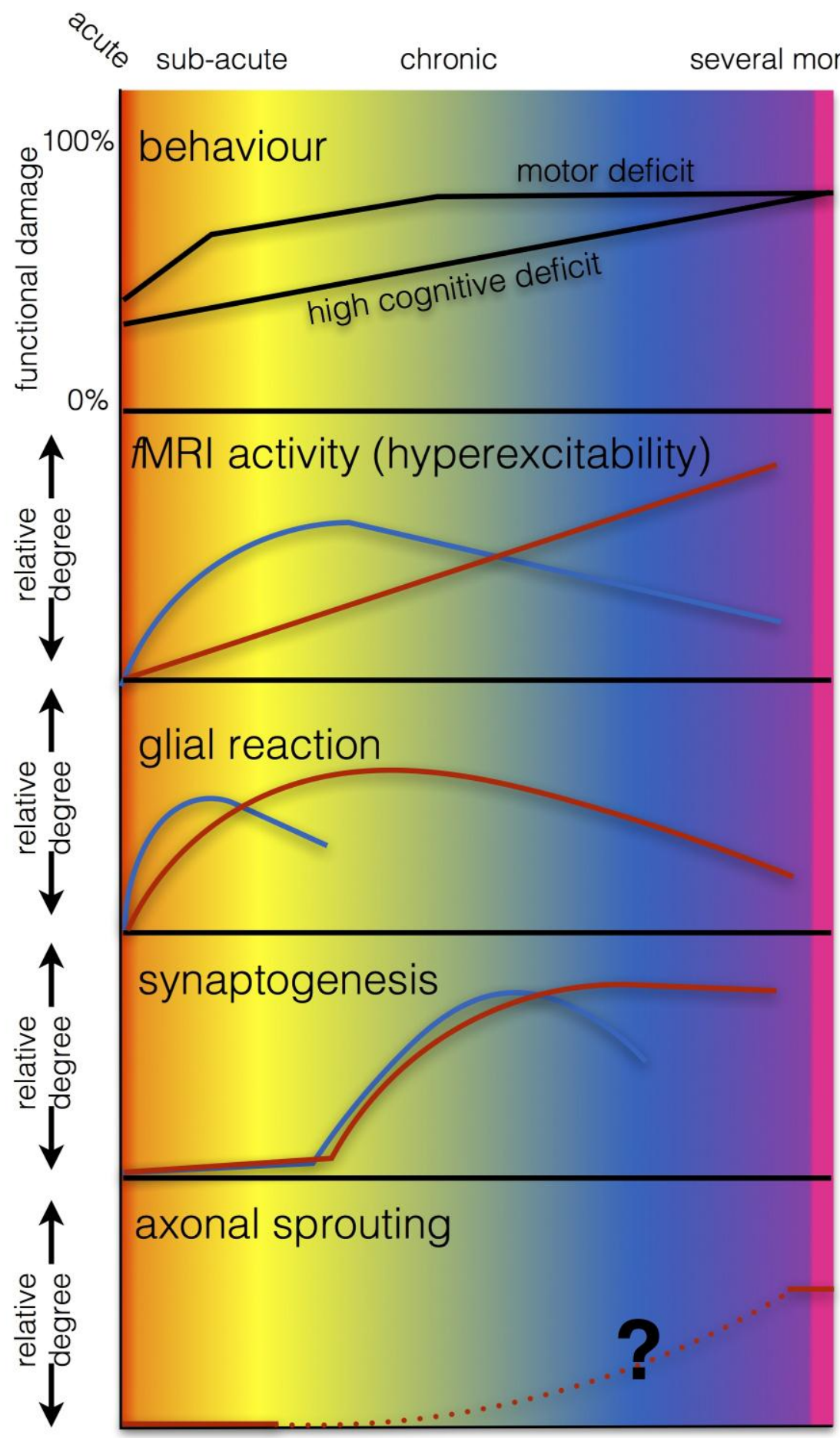

contralesional hemisphere

ipsilesional hemisphere 


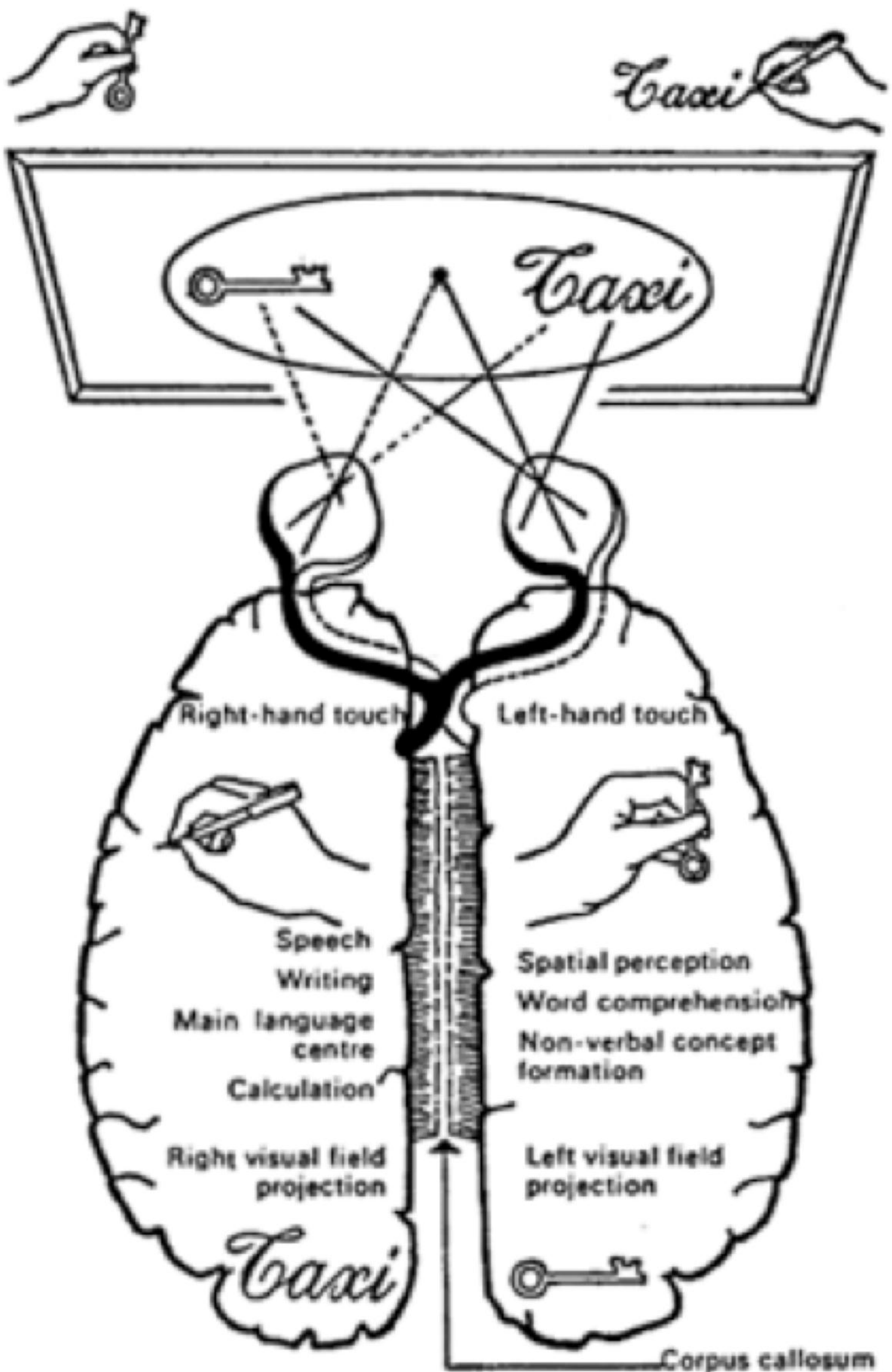




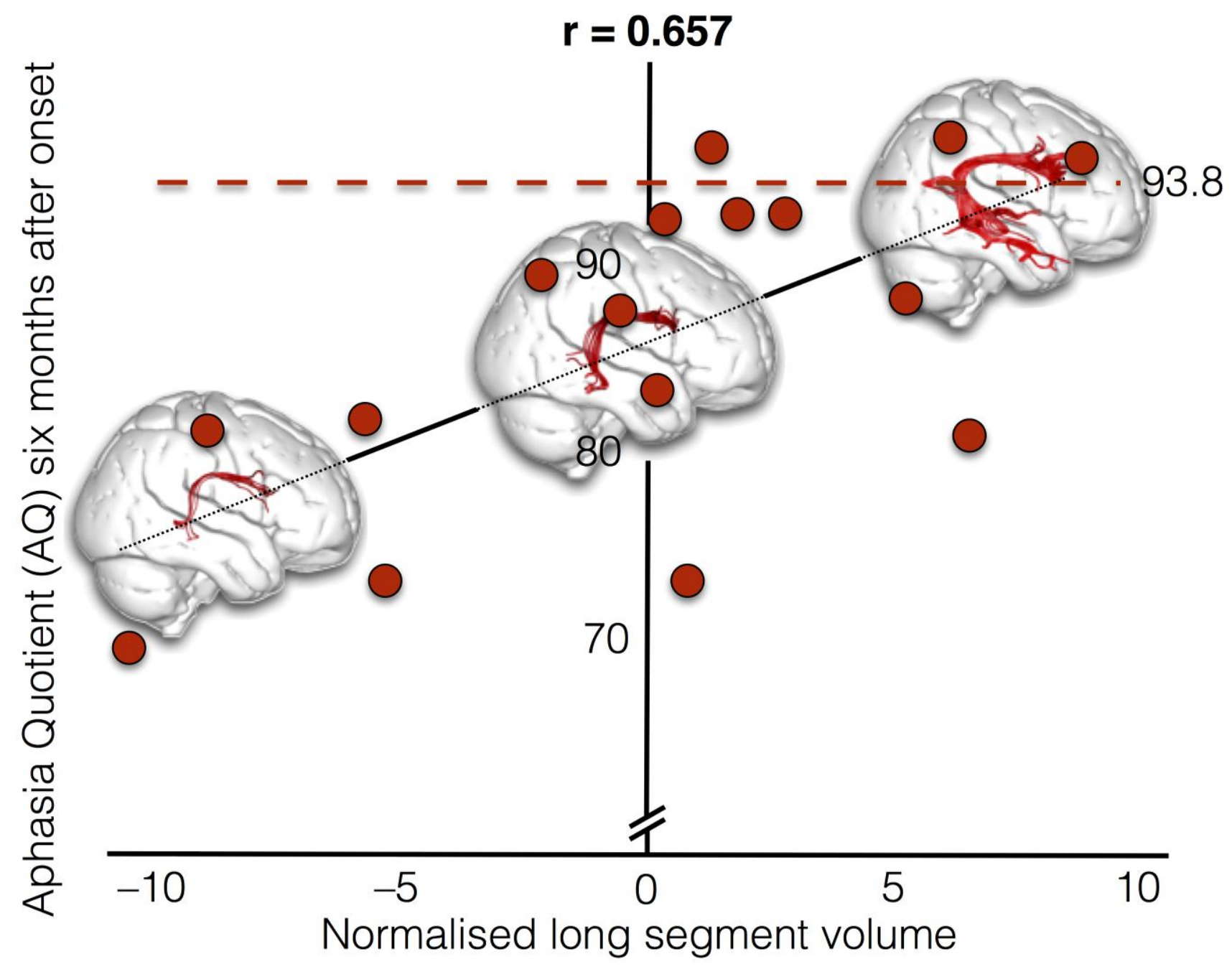

